\title{
Hegemonia e políticas sociais no Brasil: contribuições ao debate sobre vinculação orçamentária
}

\author{
Isabela Ramos Ribeiro \\ Universidade de Brasília, Departamento de Serviço Social, Brasília, \\ $\mathrm{DF}$, Brasil (UnB)
}

\author{
Evilasio da Silva Salvador \\ Universidade de Brasília, Departamento de Serviço Social, Programa \\ de Pós-Graduação em Política Social, Brasília, DF, Brasil (UnB)
}

\begin{abstract}
Hegemonia e políticas sociais no Brasil: contribuições ao debate sobre vinculação orçamentária Resumo: Este artigo tem por objetivo evidenciar como a vinculação orçamentária para as políticas sociais facilita ou dificulta o atendimento aos interesses da burguesia e suas frações, destacando como ilustração as diferenças entre a política educacional, com vinculação orçamentária, e a política habitacional, que não possui tal obrigatoriedade. Para isso, trabalham-se os pressupostos com relação ao Estado e seu papel na garantia das condições de produção e na manutenção da hegemonia burguesa, especialmente a partir da destinação do fundo público às distintas frações da burguesia. Em seguida, são apresentadas as diferentes visões acerca da vinculação orçamentária e os financiamentos das políticas sociais, para posteriormente apresentar os dados sistematizados a partir do orçamento público e do Demonstrativo de Gastos Tributários (renúncias tributárias) entre os anos de 2003 e 2015, buscando evidenciar o espaço para a reprodução do capital nas políticas de educação e habitação, ainda que com diferenças em grau devido à vinculação de recursos ou sua ausência.
\end{abstract}

Palavras-chave: Política social. Hegemonia. Vinculação orçamentária. Educação. Habitação.

\section{Hegemony and Social Policies in Brazil: Contributions to the debate about mandatory budget allotments}

Abstract: The purpose of this article is to reveal how mandatory budget allotments for social policies facilitate or impede attending the interests of the bourgeoisie and its fractions, highlighting as an example the differences between educational policy, for which there are mandatory spending requirements, and housing policy, which does not have this obligation. To do so, it looks at the presumptions in relation to the state and its role in guaranteeing the conditions of production and maintenance of bourgeois hegemony, especially through the use of allocation of government funds to distinct factions of the bourgeoisie. The article then presents different visions about the budget ties and financing of social policies and then presents systematized data based on the government budget and Statements on Tax Spending (fiscal exemptions) from 2003 until 2015, to reveal the space for the reproduction of capital in educational and housing policies, even if with differences in degree due to mandatory budget allocations or not.

Keywords: Social policy. Hegemony. Budget obligations. Education. Housing.

Recebido em 15.06.2017. Aprovado em 05.09.2017. Revisado em 17.11.2017.

(C) O(s) Autor(es). 2018 Acesso Aberto Esta obra está licenciada sob os termos da Licença Creative Commons Atribuição-NãoComercial 4.0 Internacional (https://creativecommons.org/licenses/bync/4.0/deed.pt_BR), que permite copiar, distribuir e reproduzir em qualquer meio, bem como adaptar, transformar e criar a partir deste material, desde que para fins não comerciais, e que você forneça o devido crédito aos autores e a fonte, insira um link para a Licença Creative Commons e indique se mudanças foram feitas. 


\section{Introdução}

A constituição e recomposição da hegemonia burguesa pressupõe a apropriação do fundo público, e nesse processo algumas frações das classes dominantes são mais privilegiadas, especialmente por conta dos investimentos públicos relacionados ao desenvolvimento de políticas públicas econômicas e sociais, além de subsídios, desonerações tributárias, entre outros. Assim, cabe o questionamento sobre quais grupos são beneficiados, e em que medida tais benefícios influenciam a conformação das políticas sociais no Brasil. A vinculação de recursos públicos para as áreas sociais foi uma das alternativas para enfrentar a perversa tradição do orçamento fiscal brasileiro. Justifica-se, assim, a necessidade de verificar a relação entre as políticas com vinculação orçamentária e as que não possuem vinculação, buscando evidenciar como isso se expressa de formas diferentes na apropriação do fundo público pelo capital.

As políticas que compõem a seguridade social - saúde, previdência e assistência social-, e a política de educação possuem vinculação orçamentária obrigatória, que foi uma conquista na Constituição Federal (CF) de 1988. Essa vinculação orçamentária se traduz por fontes tributárias exclusivas para o financiamento como é o caso das políticas sociais que integram a seguridade social no orçamento da União, que têm asseguradas as contribuições sociais determinadas no artigo 195 da CF. Outra forma de vinculação dos recursos orçamentários são os gastos mínimos obrigatórios que são determinados para todos entes da federação, no caso das políticas de educação e saúde.

Nesse escopo, embora existam inúmeras formas de apropriação pelo capital dos recursos do fundo público direcionados para essas políticas - tais como a Desvinculação de Recursos da União (DRU), privatização dos serviços de saúde e educação, fundos de pensão privados e demais aspectos que transferem valor especialmente ao capital portador de juros -, nas políticas em que não há obrigatoriedade de vinculação de gastos e receitas, o financiamento, por estar ainda mais sujeito à correlação de forças sociais, tende a ser balizado por interesses do capital na articulação da hegemonia, a exemplo da habitação, saneamento, urbanismo, direitos de cidadania e organização agrária. Essas políticas, por estarem submetidas à vontade do governante na alocação orçamentária, não são universais e não contam com dispêndios regulares no orçamento público.

Neste artigo, busca-se realizar uma análise comparativa entre duas políticas sociais que possibilite visualizar as diferenças - no âmbito do orçamento e, portanto, na eleição de prioridades dos governos - entre uma política com vinculação orçamentária e outra sem qualquer tipo de vinculação obrigatória; daí a escolha pelas políticas de educação e habitação. Dentre os elementos levados em consideração para a análise comparativa, destacam-se as diferenças entre as formas de financiamento de cada uma das duas políticas, a evolução da execução orçamentária das funções orçamentárias, a participação dos valores pagos no orçamento executado e o volume das desonerações tributárias realizadas. O estudo privilegiou o período entre 2003 e 2015, anos em que o Partido dos Trabalhadores (PT) esteve no governo federal dando destaque ao projeto de conciliação de classes a partir das políticas sociais orientadas para a ampliação do mercado consumidor via concessão de crédito. Tal processo, ilustrado pelas políticas de educação e habitação, permite explicitar a efetivação de programas que possibilitaram o acesso à educação superior e a aquisição de moradias, ao passo em que beneficiaram o capital portador de juros e as frações industrial e de serviços, além do grande volume de recursos direcionado para o sistema da dívida pública.

Assim, o presente trabalho tem por objetivo evidenciar como a vinculação orçamentária para as políticas sociais facilita ou dificulta o atendimento aos interesses da burguesia e suas frações, destacando como ilustração as diferenças entre a política educacional, com vinculação orçamentária, e a política habitacional, que não possui esta obrigatoriedade. O texto está organizado em duas seções. Na primeira, trabalham-se os pressupostos com relação ao Estado e seu papel na garantia das condições de produção e na manutenção da hegemonia burguesa, especialmente a partir da destinação do fundo público às distintas frações da burguesia, e em particular ao capital portador de juros. Na segunda seção, são apresentadas as diferentes visões acerca da vinculação orçamentária, para posteriormente apresentar os dados sistematizados a partir do orçamento público e do Demonstrativo de Gastos Tributários (renúncias tributárias), buscando evidenciar o espaço para a reprodução do capital nas políticas de educação e habitação, ainda que com diferenças em grau devido à vinculação de recursos ou sua ausência.

\section{Hegemonia, fundo público e financiamento das políticas sociais}

A hegemonia, para Gramsci (2000), caracteriza-se como a capacidade de aglutinar e conduzir grupos sociais em torno de um projeto que abarque as dimensões política, econômica e cultural. No capitalismo, o projeto societário dominante é conduzido pela burguesia, a qual se utiliza de inúmeros mecanismos a partir de sua organização no âmbito da sociedade civil, culminando na condensação de seus interesses na esfera estatal. 
Nas palavras de Gramsci, o Estado consiste em "todo o complexo de atividades práticas e teóricas com os quais a classe dirigente não só justifica e mantém o seu domínio, mas consegue obter o consenso ativo dos governados." (GRAMSCI, 2000, p. 331).

No Brasil, o planejamento estatal sempre atendeu ao objetivo do desenvolvimento capitalista, da satisfação dos interesses do setor privado e dos pactos de dominação indispensáveis à manutenção da hegemonia burguesa. (IANNI, 1986). No entanto, sendo o Estado expressão da luta de classes, é espaço contraditório aberto às necessidades de reprodução do capital, mas também da força de trabalho.

O fato da hegemonia pressupõe indubitavelmente que sejam levados em conta os interesses e a as tendências dos grupos sobre os quais a hegemonia será exercida, que se forme um certo equilíbrio de compromisso, isto é, que o grupo dirigente faça sacrifícios de ordem econômico-corporativa; mas também é indubitável que tais sacrifícios e tal compromisso não podem envolver o essencial, dado que, se a hegemonia é éticopolítica, não pode deixar de ser também econômica, não pode deixar de ter seu fundamento na função decisiva que o grupo dirigente exerce no núcleo decisivo da atividade econômica. (GRAMSCI, 2000, p. 48).

O processo de acumulação do capital e a manutenção da extração de mais-valia a partir das relações de exploração da força de trabalho exigem a apresentação dos interesses burgueses como interesses universais, permitindo visualizar a relação entre o processo de acumulação e a hegemonia. Para Gramsci, é possível a construção de uma nova hegemonia por parte das classes subalternas, a partir de sua organização nos aparelhos privados de hegemonia, procurando evidenciar os limites do projeto burguês e seus interesses de classe representados no Estado ampliado. Por isso, no âmbito do planejamento e execução das políticas sociais sempre associadas às políticas econômicas - não se pode perder de vista as potencialidades de tensionamento ao capital e disputa sobre os gastos sociais.

A participação concreta do Estado na garantia das condições para o desenvolvimento do capitalismo e na reprodução das relações sociais torna-se visível a partir da constituição e apropriação do fundo público. Considerando que a disputa pelos recursos do fundo público ocorre no âmbito do orçamento estatal (SALVADOR, 2012), demarca-se a necessidade de compreender o papel do orçamento no planejamento de políticas sociais no capitalismo dependente brasileiro. Parte-se do pressuposto de que a luta de classes nas economias dependentes se configura de maneira diferente dos países centrais, pois, de acordo com Marini (2011), se baseiam nos mecanismos de transferência de valor decorrente da troca desigual e a consequente superexploração da força de traba1ho. Assim, o processo de acumulação - e por consequência, também os recursos disponíveis do fundo público carrega peculiaridades por conta do desenvolvimento econômico subordinado nessas formações sociais, que levam a especificidades na conformação do Estado e, portanto, na luta e definição das políticas sociais.

A base do poder econômico se constitui na sociedade civil e se concretiza no Estado, por meio de normas, legislações, forças armadas, políticas públicas, dentre outras formas. Dessa maneira, a classe dominante se apropria dos recursos concentrados na esfera estatal, interferindo na conformação das políticas públicas econômicas e sociais. Por essa razão, ressalta-se a necessidade de investigar o orçamento e seus respectivos mecanismos. Boschetti (2009) traz importantes indicações quanto a isso, ao afirmar a necessidade de buscar, na avaliação das políticas, programas e projetos sociais, as fontes de financiamento, direção e magnitude dos gastos, os quais, articulados com outros aspectos, possibilitam análises que situam a avaliação das políticas sociais nas relações contraditórias entre Estado e sociedade civil no capitalismo.

Salvador (2010) evidencia que, além do financiamento da política social, o fundo público cumpre outros destinos referentes ao funcionamento da acumulação de capital e às facilidades que o Estado proporciona às empresas capitalistas, tanto nacionais como estrangeiras, contribuindo ativamente para a manutenção da hegemonia burguesa por meio da política econômica. Os recursos manejados pelo Estado por meio da política fiscal e tributária referem-se à arrecadação e aos gastos, relacionando-se com as fontes de financiamento e direcionamento dos investimentos, respectivamente.

Por essas razões, é necessário verificar em que medida o Estado vem financiando as diversas frações do capital e como isso tem auxiliado na consolidação da hegemonia burguesa, seja por investimentos diretos via políticas econômicas e sociais, desonerações tributárias ou emissão títulos da dívida pública, com destaque para a transferência de recursos ao capital portador de juros. Segundo Carcanholo e Nakatani (2015), uma das características que define o capitalismo contemporâneo é a financeirização ou generalização do movimento especulativo do capital. Na busca pela compreensão desse processo, os autores afirmam que

o capital especulativo parasitário resultaria da conversão da forma autonomizada do capital a juros ou capital portador de juros, ou mais precisamente do capital fictício, quando este ultrapassa os limites do que é necessário para o funcionamento normal do capital industrial. (CARCANHOLO; NAKATANI, 2015, p. 33). 
Nos termos de Marx (2008), o capital pode deslocar-se de uma situação para outra, embora tenha origem sempre e necessariamente na extração de mais-valia. Por isso, o significado social da existência do capital fictício, acoplado ao capital portador de juros, é um aprofundamento da exploração e subalternização dos/as trabalhadores/as, com vistas à remuneração de todas as frações do capital.

Com relação ao serviço da dívida, Salvador (2010) explicita que, no Brasil, o pagamento de juros da dívida pública é destinado ao setor financeiro, o qual vive às custas do fundo público brasileiro, comprometendo uma parcela importante dos orçamentos da seguridade social e fiscal. Com isso, evidencia-se a participação direta dessa forma do capital na economia e no aumento da exploração sobre os/as trabalhadores/as, pois a lógica especulativa gera instabilidade e crises. (CARCANHOLO; NAKATANI, 2015).

Segundo Paulani (2010), a participação ativa do Estado brasileiro no processo de valorização financeira está associada ao discurso dominante de que a crise causa um estado de emergência econômico permanente, exigindo como resposta o ajuste fiscal. A autora explicita que o acesso privilegiado a informações sobre papéis públicos, concorrências públicas, fundos contábeis e vendas de ativos públicos torna-se fundamental para evitar riscos ao capital fíctício. Conforme Paulani (2010, p. 131), “o poder público maneja negócios e recursos sempre volumosos, de modo que atrelar o rentismo ao poder do Estado parece a forma mais segura de aliar retorno elevado e liquidez a segurança".

Sob o predomínio do capital portador de juros - com suas derivações tais quais o capital fíctício e o capital especulativo parasitário -, a contrarreforma do Estado (BEHRING, 2003) impõe um ajuste físcal permanente para as áreas sociais, sendo uma de suas expressões a busca pela desvinculação dos recursos destinados constitucionalmente para as políticas de seguridade social e educação, o que garantiria a efetivação destes direitos fundamentais mesmo frente a cenários de redução de gastos e cortes no orçamento público. Cabe observar, então, como tem se realizado a distribuição de recursos para as políticas sociais, destacando as diferenças entre as que possuem vinculação orçamentária e as que não possuem tal obrigatoriedade, posto que os decretos de contingenciamento do orçamento são instrumentos utilizados para aumentar o superávit primário, os quais "reduzem os valores autorizados a serem gastos pelos órgãos do governo e atingem, sobretudo, aquelas funções orçamentárias que não têm gastos obrigatórios ou vinculados". (SALVADOR, 2010, p, 189).

No entanto, existem diversas críticas dirigidas às receitas vinculadas, alegando que engessam o orçamento $\mathrm{e}$ impossibilitam autonomia e flexibilidade da política fiscal. Nas palavras de Sousa (2008, p. 30), "o grau de comprometimento das receitas públicas, definido constitucionalmente, reduziu significativamente o potencial de condução da política econômica", obrigando a realização de determinados tipos de gastos, numa "tentativa de enfraquecimento do poder Executivo perante o legislativo" (SOUSA, 2008, p. 33). Para este autor, a resposta acertada frente à crescente rigidez orçamentária foi a criação de mecanismos de desvinculação de recursos orçamentários, sem destinação específica ou transferência para os entes federativos. Como resposta a esse tipo de demanda, na década de 1990 foi criado o Fundo Social de Emergência (FSE), posteriormente transformado na DRU, "que passou a destinar 20\% das receitas arrecadadas em nome das políticas sociais para o atendimento de outras prioridades fiscais, como a geração de superávits primários.” (INSTITUTO DE PESQUISA ECONÔMICA APLICADA, 2010, p. 90).

Assim, são realizados cortes orçamentários com vistas à redução da vinculação de receitas para as áreas sociais, que perduram até os dias atuais por meio da DRU, renovada em 2016 com aumento da alíquota de desvinculação de $20 \%$ para $30 \%$, com vigência até 2023 , recaindo sobre as receitas de impostos, contribuições sociais e contribuições econômicas que deveriam estar direcionadas à seguridade social e à educação.

Mesmo com tamanha retirada de recursos das áreas sociais, autores como Sousa (2008, p. 43, grifos nossos) alegam que "reduzir a rigidez orçamentária consistiria em reduzir ou, preferencialmente, eliminar as vinculações de recursos, ampliando-se as receitas livres". O autor defende, ainda, a necessidade de ir além da DRU para resolver a questão de flexibilidade da política fiscal, por meio da revisão da legislação orçamentária e de uma reforma tributária, ambas relacionadas a "mudanças estruturais que permitam aumentar a capacidade de o governo federal atender a outras demandas da sociedade e não somente àquelas vinculadas". (SOUSA, 2008, p. 44). Essas outras demandas, diz o autor, referem-se à "consecução dos projetos prioritários do governo e constituição da poupança necessária à redução da dívida pública" (SOUSA, 2008, p. 44), beneficiando uma pequena parcela da população favorecida pelo pagamento de juros e amortizações da dívida, em detrimento de milhões de trabalhadores/as brasileiros/as.

Este mecanismo representa um retrocesso para os direitos sociais conquistados e garantidos constitucionalmente, em prol do capital portador de juros e do capital especulativo parasitário. Em acordo com Salvador (2010, p. 369), "a principal consequência da DRU é o desvio regular de bilhões de reais da saúde, educação, previdência e assistência social, que são transferidos por meio do orçamento fiscal para os mercados financeiros". Por essas razões, e a partir do pressuposto de que o orçamento público é um espaço de luta política (SALVADOR, 2012), é fundamental a luta e resistência para a manutenção de receitas vinculadas que garantam a concretização das políticas sociais necessárias à reprodução da vida das classes subalternas. Nesse 
aspecto, destaca-se que mesmo sob fortes ataques neoliberais, a política educacional mantém certa regularidade na execução orçamentária, se comparada a políticas sem vinculação obrigatória, tal qual a política de habitação, como será demonstrado no item a seguir.

\section{As políticas de educação e habitação (2003-2015): análise comparativa das funções orçamentárias}

As políticas sociais de educação e habitação, segundo Salvador (2012), são financiadas no âmbito do orçamento fiscal. Isso significa que a maior parte dos recursos para seu financiamento são provenientes dos impostos, e com relação à educação, os impostos esses são agrupados em duas fontes dentro do orçamento público: recursos ordinários e recursos destinados à Manutenção e Desenvolvimento do Ensino (MDE). Dessa forma, a promoção da educação é responsabilidade do Estado, a partir da distribuição entre os entes federativos: os municípios devem priorizar a educação infantil e ensino fundamental; os estados responsabilizam-se prioritariamente pelo ensino fundamental e médio; a União arca com o ensino técnico e superior. As lutas travadas pelos movimentos populares em favor da educação, no período da Constituinte, levaram ao seu reconhecimento como um direito, e para sua efetivação com qualidade foi estabelecida a vinculação mínima de impostos $^{1}$, de $18 \%$ para a União e $25 \%$ para os estados, o Distrito Federal e os municípios. Além disso, a educação básica pública tem a contribuição social do salário-educação como fonte adicional de financiamento, recolhida pelas empresas e repassada ao consumo, constituindo-se em um tributo regressivo.

Bastos e Cardozo (2010, p. 5) ressaltam que "nos momentos em que vigorou a vinculação, os recursos atingiram níveis mais elevados, o contrário ocorrendo quando esta não existia ou era suprimida dos textos constitucionais", como no período de 1967-1988, quando os governos militares suprimiram a vinculação de receitas para a educação.

Já nos anos 1990, estudo do Instituto de Pesquisa Econômica Aplicada (IPEA) (2010) destaca que foram criados fundos de custeio para garantir o acesso aos serviços de educação, como o Fundo de Manutenção e Desenvolvimento do Ensino Fundamental e de Valorização do Magistério (FUNDEF), posteriormente substituído pelo Fundo de Manutenção e Desenvolvimento da Educação Básica e de Valorização dos Profissionais da Educação (FUNDEB). Nota-se, então, a criação de fundos e programas específicos com destinação garantida de recursos orçamentários, o que resultou numa ampliação considerável do número de matrículas no decorrer das últimas duas décadas.

Por outro lado, a política habitacional não possui receitas vinculadas no orçamento público e suas fontes de financiamento são mais pulverizadas. Conforme Ferraz (2011), a atuação do Estado no financiamento da habitação é direcionada para a população de baixa renda - característica de uma política social seletiva - e pode ocorrer por limitação dos preços dos aluguéis, subsídio de empréstimos com baixas taxas de juros para as construções habitacionais ou subsídio para o pagamento de aluguéis por meio de benefícios vinculados a essa finalidade. Segundo a autora, o Fundo de Garantia por Tempo de Serviço (FGTS) é uma fonte importante de financiamento ao setor habitacional de interesse social, "constituindo-se tradicionalmente em um fluxo regular de recursos para esse setor bem como para as áreas de saneamento e infraestrutura urbana" (FERRAZ, 2011, p. 68-69), embora seus recursos tenham sido subutilizados a partir de meados da década de 1990, com a realocação de parte desses recursos - os quais deveriam ser destinados para o financiamento de habitação popular - para títulos da dívida pública.

O financiamento habitacional conta, ainda, com o Sistema Brasileiro de Poupança e Empréstimo (SBPE), que "representa a principal fonte de recursos privados destinados ao financiamento de operações de crédito imobiliário." (FERRAZ, 2011, p. 72). Seus recursos são direcionados à aquisição de imóveis novos, aquisição de imóveis usados e construção de novas unidades, sendo o financiamento da aquisição responsável pela maior parte dos recursos do SBPE. Entretanto, como destacam Royer, Gomes e Pereira (2013), também os recursos do SBPE passaram a ser utilizados, na década de 1990, como instrumento da política monetária e da estabilização econômica, em detrimento do direcionamento de recursos para a política habitacional.

Ambos, FGTS e SBPE compõem o Sistema Financeiro de Habitação (SFH), criado em 1964 e principal responsável pelo financiamento habitacional no Brasil, baseado no crédito. Além do SFH, instituiu-se, a partir de 1997, uma nova forma de financiamento que visava ampliar a relação entre o mercado de capitais e o mercado imobiliário, o Sistema Financeiro Imobiliário (SFI). O SFI abre espaço para a participação de investidores privados e está alicerçado na captação de recursos junto ao mercado de capitais por meio da securitização, buscando garantir a segurança jurídica das transações. A partir da aplicação dessa lei, se consolidou no Brasil "a reprodução do capital financeiro por meio do espaço construído.” (ROYER; GOMES; PEREIRA, 2013, p. 14).

Nesse sentido, Shimbo (2010) demonstra que, desde o governo FHC, além da ampliação da participação do setor privado, duas frentes se abriram para a política habitacional: a descentralização da alocação dos recursos 
federais e a introdução de política de crédito para o mutuário final. Estes elementos "abriram as portas para a centralidade da dinâmica privada na provisão habitacional brasileira" (SHIMBO, 2010, p. 66). É neste contexto que se constitui a política habitacional e o Programa Minha Casa Minha Vida (PMCMV) durante o governo Lula, no fluxo da lógica orientada para o mercado que vinha se desenhando desde meados dos anos 1990.

Com essas considerações, observa-se a instabilidade e irregularidade do financiamento habitacional no Brasil, em parte devido à ausência de vinculação orçamentária obrigatória, possibilitando maior intervenção do capital nas políticas de habitação, conforme seus interesses de classe e a correlação de forças na constituição da hegemonia. Com intuito de demonstrar tal rebaixamento do orçamento no que se refere às políticas sem vinculação obrigatória, as tabelas 1 e 2 retratam a execução orçamentária da função Educação ${ }^{2}$ e da função Habitação, respectivamente.

Tabela 1 - Execução orçamentária da função Educação de 2003 a 2015

\begin{tabular}{|crcc|}
\hline \multicolumn{5}{c}{ Valores em milhões de R\$, deflacionados pelo IGP-DI, a preços de 2016 } \\
\hline Ano & Autorizado & Pago & Execução \\
\hline 2003 & $41.151,36$ & $35.309,81$ & $85,80 \%$ \\
2004 & $34.799,14$ & $29.765,69$ & $85,54 \%$ \\
2005 & $37.741,77$ & $28.748,62$ & $76,17 \%$ \\
2006 & $39.543,86$ & $33.044,28$ & $83,56 \%$ \\
2007 & $47.631,07$ & $38.030,63$ & $79,84 \%$ \\
2009 & $54.235,43$ & $42.998,87$ & $79,28 \%$ \\
2010 & $64.936,56$ & $50.038,01$ & $77,06 \%$ \\
2011 & $84.811,56$ & $65.222,95$ & $76,90 \%$ \\
2012 & $95.044,74$ & $71.249,83$ & $74,96 \%$ \\
2013 & $116.975,86$ & $79.846,68$ & $68,26 \%$ \\
2014 & $118.255,15$ & $86.749,85$ & $73,36 \%$ \\
2015 & $127.136,02$ & $100.409,66$ & $78,98 \%$ \\
\hline
\end{tabular}

Fonte: Brasil(2016a). Elaboração própria.

Tabela 2 - Execução orçamentária da função Habitação de 2003 a 2015

\begin{tabular}{crcc}
\hline \multicolumn{5}{c}{ Valores em milhões de R\$, deflacionados pelo IGP-DI, a preços de 2016 } \\
\hline Ano & Autorizado & Pago & Execução \\
2003 & $1.020,37$ & 30,08 & $2,95 \%$ \\
2004 & $1.769,18$ & 508,86 & $28,76 \%$ \\
2005 & $1.477,35$ & 301,70 & $20,42 \%$ \\
2006 & $2.939,31$ & 132,50 & $4,51 \%$ \\
2007 & $1.943,01$ & 0,48 & $0,02 \%$ \\
2008 & $2.297,80$ & 274,02 & $11,93 \%$ \\
2009 & $1.989,65$ & 220,90 & $11,10 \%$ \\
2010 & 501,08 & 34,15 & $6,81 \%$ \\
2011 & $1.071,29$ & 89,96 & $8,40 \%$ \\
2012 & $1.056,56$ & 186,87 & $17,69 \%$ \\
2013 & 386,97 & 15,11 & $3,91 \%$ \\
2014 & 469,23 & 9,26 & $1,97 \%$ \\
2015 & 215,39 & 2,82 & $1,31 \%$ \\
\hline
\end{tabular}

Fonte: Brasil(2016a). Elaboração própria.

A partir da leitura da tabela 2, nota-se a baixíssima execução dos valores pagos em relação aos autorizados para a função habitação, além de grande oscilação de um ano para outro, com a média de execução de 9,21\% no período 2003-2015. Já na função educação (tabela 1), a execução se mantém mais regular e com 
uma média de 78,19\% no mesmo período. Ressalta-se ainda o montante de gastos para a função educação, bastante superior à habitação.

A vinculação de recursos orçamentários, não só garantiu a maior regularidade na execução financeira dos recursos da educação na esfera da União, como o maior aporte, em termos reais, no período de 2003 a 2015. De acordo com a tabela 1, o orçamento pago da educação no período em tela apresentou um crescimento de 195,57\%, acima da inflação medida pelo Índice Geral de Preços - Disponibilidade Interna (IGP-DI). Quanto à função orçamentária habitação, a tabela 2 revela que de 2003 a 2015, além do comportamento errático na execução financeira desta política, ocorreu um encolhimento, em termos reais, dos valores pagos no orçamento da União, decrescendo de $\mathrm{R} \$ 30,08$ milhões (2003) para $\mathrm{R} \$ 2,82$ milhões (2015), isto é, um decréscimo de 90,64\%.

Salvador (2010, p. 189) afirma que "os gastos orçamentários com previdência, assistência, saúde, educação e trabalho conseguem preservar a sua execução, pois têm a maior parte dos recursos de natureza obrigatória, ou seja, sua execução está vinculada a preceitos constitucionais ou a alguma norma legal". O autor destaca que o contingenciamento orçamentário costuma ser utilizado pela política econômica federal para assegurar as metas de superávit primário, uma vez que a não execução integral orçamento tem efeito similar ao contingenciamento dos recursos, com a retenção de recursos para o Tesouro Nacional, contribuindo para a realização do resultado financeiro do governo federal.

É possível observar a permanência da distância abissal entre as funções habitação e educação na participação no total do orçamento, como demonstra o gráfico 1 . Tal diferença entre a magnitude dos valores tornou necessária a adoção de um eixo secundário para a representação da função habitação no gráfico 1 .

\section{Gráfico 1 - Participação dos valores pagos no orçamento executado, por função}

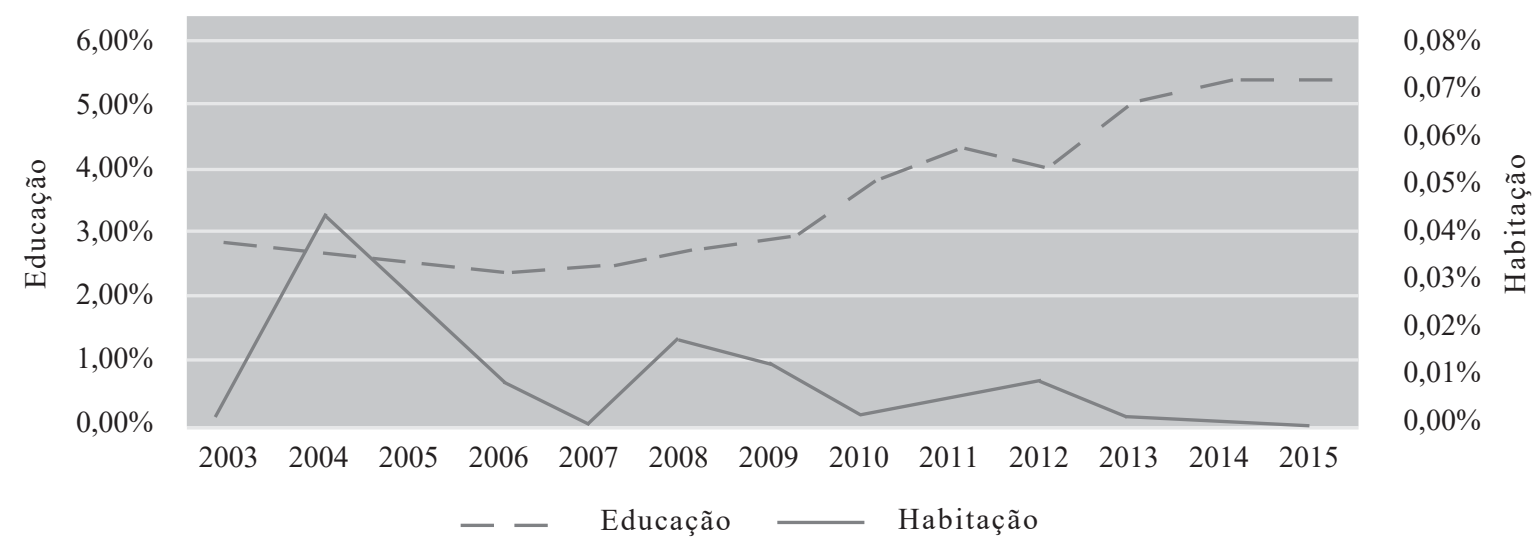

Fonte: Brasil(2016a). Elaboração própria.

Em 2004, a habitação teve participação de $0,043 \%$ no orçamento, momento em que atinge seu ápice no período. No mesmo ano, a educação contava com $2,53 \%$ de participação, 58,8 vezes mais que a função habitação. Em 2015, a função educação chega a expressar 5,23\% do orçamento, evidenciando crescimento do investimento em educação - incluídos aí os subsídios ao ensino privado. No entanto, conforme Salvador (2015), os gastos públicos com educação ainda são pequenos para efetivá-la com qualidade. Segundo o autor, "estudos apontam para a necessidade de um aporte de $10,7 \%$ do PIB, valor bem acima da proposta de $6,9 \%$ do PIB, apresentada pelo Ministério da Educação" (SALVADOR, 2015, p. 36).

Todavia, é preciso considerar a pulverização das fontes de financiamento e dos gastos, dificultando a análise da política habitacional quando limitada apenas à função habitação. O PMCMV, o qual concentrou a maior parte dos recursos destinados a essa política a partir de 2010, não está inserido na função habitação no orçamento, e sim na função encargos especiais, onde estão distribuídas as ações orçamentárias Fundo de Arrendamento Residencial (FAR), Fundo de Desenvolvimento Social (FDS) e subvenções econômicas, responsáveis pelo financiamento do Programa. De acordo com Melo (2016, p. 95), "até 2011, essas ações orçamentárias estavam inseridas no programa 0909 - operações especiais: outros encargos especiais. A partir de então, o PMCMV foi inserido no PPA como eixo do PAC e passou a ser designado pelo programa 2049 moradia digna no orçamento público.”

Outro aspecto analisado para compreender a articulação da hegemonia burguesa no Brasil são as desonerações tributárias, que favorecem diretamente o grande capital. De acordo com documento da Receita 
Federal (RFB), as desonerações tributárias, as quais são conceitualmente chamadas de gastos tributários, indicam os gastos indiretos do governo que se realizam por meio do sistema tributário, e "são explicitados na norma que referencia o tributo, constituindo-se uma exceção ao sistema tributário de referência, reduzindo a arrecadação potencial e, consequentemente, aumentando a disponibilidade econômica do contribuinte" (RFB, 2016, p. 10). Podem ser de caráter compensatório, quando o governo não atende adequadamente a população dos serviços de sua responsabilidade - tais como gastos com educação e saúde, ou caráter incentivador, quando o governo tem a intenção de desenvolver determinado setor ou região. A Secretaria da Receita Federal disponibiliza o volume das desonerações por meio do Demonstrativo de Gastos Tributários.

O gráfico 2 expressa o volume de recursos indiretamente gastos pelo Estado ao abrir mão da arrecadação com a política de desonerações, nas funções educação e habitação. Como delineado por Salvador (2015, p. 13), a análise das renúncias tributárias compreende o financiamento indireto da política social, e "torna possível identificar a transferência indireta e extraorçamentária de recursos para o setor privado." Como se pode observar, ambas as funções sofrem desonerações crescentes, e a partir de 2012 nota-se uma aproximação entre os valores desonerados das duas funções. Isso significa que as frações industriais da burguesia associadas à provisão habitacional - setor da construção civil -, foram favorecidas com a isenção de parte dos impostos.

\section{Gráfico 2 - Desonerações tributárias, por função, em R\$ de 2015 deflacionados pelo IGP-DI}

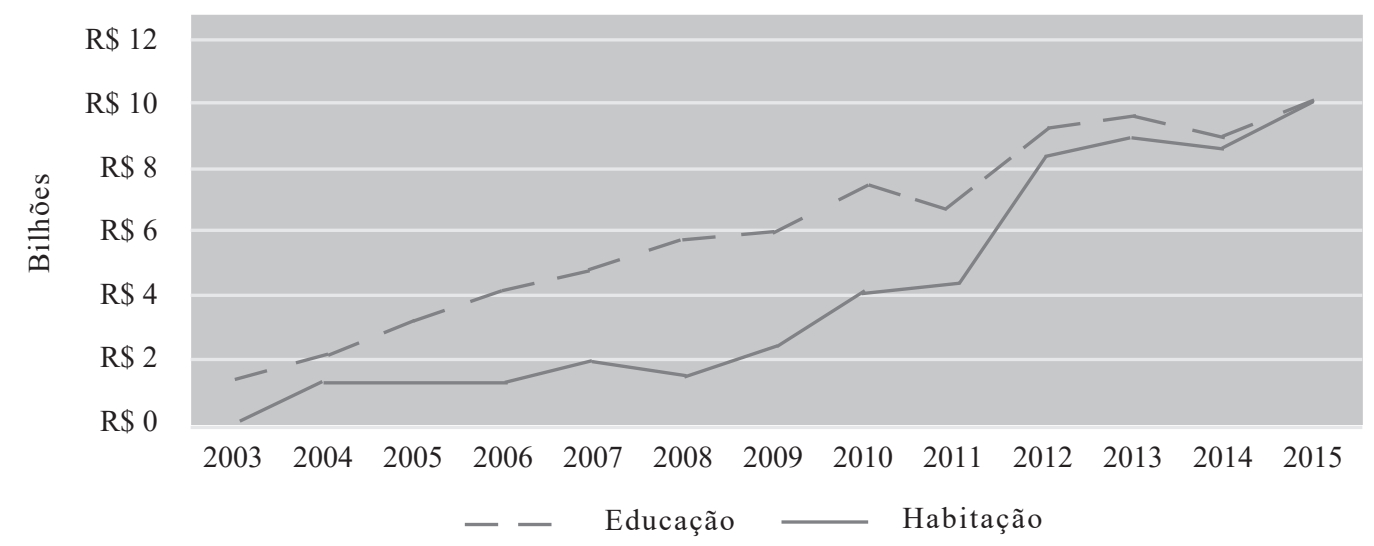

Fonte: RFB(2016). Elaboração própria.

Com relação às desonerações na educação, Salvador (2015, p. 28) explicita que são derivadas "principalmente das deduções no imposto sobre a renda da pessoa física e da imunidade tributária das entidades educacionais sem fins lucrativos." O crescimento das desonerações na função educação também expressa um crescimento do ensino privado, a partir da criação, em 2004, do Programa Universidade para Todos (PROUNI). As instituições privadas de ensino superior oferecem bolsas de estudo, ao passo em que usufruem de isenções de tributos.

Merece destaque o processo de mercantilização e financeirização dos serviços educacionais, levado a cabo por grandes conglomerados empresariais oligopolizados que passam a investir no mercado de ações internacional, pautando a educação segundo interesses do capital monetário. Este processo é estimulado pelo Estado, por meio das políticas públicas voltadas à educação, as quais oferecem facilidades para expansão do ensino privado com a liberalização dos serviços e as desonerações fiscais (VALE et al, 2015). Como consequência, prevalece a lógica do ensino aligeirado e precarizado, sem vinculação com a pesquisa e a extensão.

Embora ambas as funções - educação e habitação - tenham se aproximado no volume de desonerações tributárias $^{3}$, o montante executado no orçamento referente à habitação é imensamente inferior ao montante destinado à educação. Tal aspecto valida a importância da manutenção da vinculação obrigatória de receitas para a educação, uma vez que sem este mecanismo não há garantia de execução orçamentária e, por consequência, da efetivação das políticas sociais.

\section{Considerações finais}

As diversas frações do capital, com destaque para o capital portador de juros, encontram maneiras de condensar seus interesses no Estado, consolidando a hegemonia a partir da apropriação do fundo público e da 
influência na definição das políticas sociais, além de ganhos efetivos quando são isentas no pagamento de impostos e contribuições. Assim, o crescimento das desonerações para as funções habitação e educação tem favorecido as frações industrial e de serviços da burguesia, bem como a fração rentista. Contudo, as vinculações orçamentárias são barreiras para a expansão ainda maior do capital sobre os direitos sociais, o que fica claro quando intelectuais orgânicos associados às classes dominantes defendem a eliminação das receitas vinculadas, com vistas à ampliação da autonomia e redução da rigidez orçamentária. Tais interesses visam reduzir direitos, salários e serviços que demandem o direcionamento do orçamento para as áreas sociais, numa disputa clara sobre os destinos do fundo público.

Por fim, convém destacar que com a implantação de um novo regime fiscal (BRASIL, 2016b) ficará inviabilizada a vinculação dos recursos para as políticas sociais nos moldes desenhado na CF de 1988, ao congelar as chamadas despesas primárias do governo (exceto as despesas financeiras com o pagamento de juros da dívida) por 20 anos, limitando-se a correção pela inflação medida pelo Índice de Preços ao Consumidor Amplo (IPCA), com previsão de uma revisão em 10 anos. Tal projeto configura uma nova ofensiva do capital no desmonte da espinha dorsal do já precário Estado Social brasileiro.

No contexto brasileiro atual de ruptura democrática, o discurso do estado de emergência econômico permanente fica ainda mais evidente. As propostas de contrarreformas em curso no Brasil têm por objetivo reduzir os gastos com políticas sociais, ao passo em que favorece o grande capital, o que coloca a necessidade cada vez mais urgente de organização e formação da classe trabalhadora para a inserção qualificada na disputa pelo fundo público e pela construção de uma nova hegemonia.

\section{Referências}

BASTOS, J. D; CARDOZO, M. J. Financiamento da educação básica no Brasil: uma análise crítica à política do FUNDEF. In: ENCONTRO DE PESQUISA EM EDUCAÇÃO, 6., 2010, Teresina. Anais... Teresina: UFPI, 2010. Disponível em: <http://leg.ufpi.br/ subsiteFiles/ppged/arquivos/files/VI.encontro.2010/GT.5/GT_05_07_2010.pdf>. Acesso em: 20 nov. 2016.

BEHRING, E. R. Brasil em Contra Reforma. São Paulo: Cortez, 2003.

BOSCHETTI, I. Avaliação de políticas, programas e projetos. In: CONSELHO FEDERAL DE SERVIÇO SOCIAL; ASSOCIAÇÃO BRASILEIRA DE ENSINO E PESQUISA EM SERVIÇO SOCIAL (Org.). Serviço social: direitos sociais e competências profissionais. Brasília, DF: CFESS; ABEPSS, 2009. p. 553-574.

BRASIL. Emenda Constitucional n ${ }^{\circ}$ 95/2016. Altera o ato das disposições constitucionais transitórias, para instituir o novo Regime Fiscal, e dá outras providências. Diário Oficial da União. Brasília, DF, 16 dez. 2016b. Disponível em: <http://www2.camara.leg.br/legin/fed/ emecon/2016/emendaconstitucional-95-15-dezembro-2016-784029-publicacaooriginal-151558-pl.html>. Acesso em: 20 dez. 2016.

Senado Federal. SIGA Brasil. Painel especialista. 2016a. Disponível em: <http://www9.senado.leg.br/QvAJAXZfc/ opendoc.htm?document=Senado\%2FSigaBrasilPainelEspecialista.qvw\&host=QVS\%40www9\&anonymous=true $>$. Acesso em: 20 nov. 2016. CARCANHOLO, R.; NAKATANI, P. O capital especulativo parasitário: uma precisão teórica sobre o capital financeiro, característico da globalização. In: GOMES, H. (Org.). Especulação e lucros fictícios. São Paulo: Outras Expressões, 2015. p. 31-60.

FERRAZ, C. A. Crédito, exclusão financeira e acesso à moradia: um estudo sobre financiamento habitacional no Brasil e o Programa Minha Casa Minha Vida. 2011. 127 f. Dissertação (Mestrado em Economia) - Instituto de Economia, Universidade Federal do Rio de Janeiro, Rio de Janeiro, 2011.

GRAMSCI, A. Cadernos do cárcere. Rio de Janeiro: Civilização Brasileira, 2000. v. 3.

IANNI, O. Estado e planejamento econômico no Brasil. Rio de Janeiro: Civilização Brasileira, 1986.

INSTITUTO DE PESQUISA ECONÔMICA APLICADA. Perspectivas da Política Social no Brasil. Livro 8. Brasília, DF: IPEA, 2010. p. 57-108.

MARINI, R. M. Dialética da dependência. In: TRASPADINI, R; STEDILE, J. P. Ruy Mauro Marini: vida e obra. São Paulo: Expressão Popular, 2011. p. 131-172. 
MARX, K. O Capital: crítica da economia política. Livro 3: O processo global de produção capitalista. Rio de Janeiro: Civilização Brasileira, 2008.

MELO, M. D. de. O Acesso à Habitação no Brasil em Tempos de Capitalismo Financeirizado: uma análise do Programa Minha Casa, Minha Vida. 2016. 130 f. Dissertação (Mestrado em Política Social) - Universidade de Brasília, Brasília, 2016.

PAULANI, L. Capitalismo financeiro, estado de emergência econômico e hegemonia às avessas no Brasil. In: OLIVEIRA, F. et al. (Org.). Hegemonia às avessas. São Paulo: Boitempo, 2010. p. 109-136.

RECEITA FEDERAL DO BRASIL. Demonstrativo dos Gastos Tributários - vários anos. Brasília, DF: Secretaria da Receita Federal do Brasil, 2016. Disponível em: <http://idg.receita.fazenda.gov.br/dados/receitadata/renuncia-fiscal/previsoes-ploa/arquivos-e-imagens/ demonstrativos-dos-gastos-tributarios-dgt>. Acesso em: 20 dez. 2016.

ROYER, L. O.; GOMES, A.V.; PEREIRA, A. L. S. Mercado de capitais e mercado imobiliário: a crescente importância dos títulos de base imobiliária. In: ENCONTRO NACIONAL DA ASSOCIAÇÃO NACIONAL DE PÓS-GRADUAÇÃO E PESQUISA EM PLANEJAMENTO URBANO E REGIONAL, 15., 2013. Recife. Anais... Recife: ANPUR, 2013.

SALVADOR, E. Financiamento tributário da política social no pós-real. In: . et al (Org.). Financeirização, fundo público e política social. São Paulo: Cortez, 2012. p. 123-152.

. Fundo público e seguridade social no Brasil. São Paulo: Cortez, 2010.

Renúncias tributárias. Os impactos no financiamento das políticas sociais no Brasil. Brasília, DF: INESC, 2015.

SHIMBO, L. Z. Habitação social, habitação de mercado: a confluência entre Estado, empresas construtoras e capital financeiro. 2010. 361 f. Tese (Doutorado em Arquitetura e Urbanismo) - Escola de Engenharia de São Carlos, Universidade de São Paulo, 2010.

SOUSA, F. H. de. Os efeitos da (des)vinculação dos recursos da União e a flexibilidade orçamentária. Revista Contemporânea de Contabilidade, Florianópolis, ano 5, v. 1, n. 9, p. 29-48, jan./jun., 2008. Disponível em: <https://periodicos.ufsc.br/index.php/contabilidade/ article/viewFile/2175-8069.2008v5n9p29/11075>. Acesso em: 20 nov. 2016.

VALE, A. A.; CHAVES, V. L. J.; CARVALHO, C. H. A. Financeirização da educação superior no Brasil. In: SILVA JR, J. et al. Educação superior: internacionalização, mercantilização e repercussões em um campo de disputas. Belo Horizonte: Fino Traço, 2015. p. 71-94.

\section{Notas}

1 “Contudo, é importante lembrar que, assim como as políticas da seguridade social, o financiamento da educação foi prejudicado pelos desvios de recursos realizados por meio da DRU. [...] O mecanismo é muito simples: a Constituição determina que $18 \%$ dos recursos arrecadados em impostos federais sejam aplicados em educação, mas esse valor é calculado após a retirada dos recursos da DRU. Por consequência em vez dos 18\% previstos na Carta Magna são aplicados somente 13\% em educação". (SALVADOR, 2012, p. 145). Ainda segundo este autor, a prorrogação da DRU aprovada em 2007 foi seguida por nova Emenda Constitucional, em 2008, "proibindo a incidência da DRU sobre o orçamento da educação". (SALVADOR, 2012, p. 145).

2 Os gastos explicitados neste estudo referem-se à União. Para uma análise do total investido em Educação no Brasil seria necessário observar também os gastos dos estados e municípios.

3 O crescimento das desonerações tributárias não é exclusividade da educação e habitação, pois de forma geral as desonerações tiveram uma taxa de crescimento quase três vezes maior que a arrecadação entre 2003 e 2015: 404\% frente a 154\%, respectivamente. (BRASIL, 2016b).

\section{Isabela Ramos Ribeiro}

ramosribeiro.isabela@gmail.com

Mestrado em Serviço Social pela Universidade Federal de Santa Catarina (UFSC)

Professora do Departamento de Serviço Social da Universidade de Brasília (UnB)

Evilasio da Silva Salvador

evilasiosalvador@gmail.com

Doutorado em Política Social pela Universidade de Brasília (UnB)

Professor do Departamento de Serviço Social e do Programa de Pós-Graduação em Política Social (Mestrado e Doutorado) da Universidade de Brasília (UnB)

\section{UnB}

Campus Universitário Darcy Ribeiro

ICC Norte - Asa Norte

Brasília - Distrito Federal-Brasília

CEP: 70.910-900 